\title{
Tempo de destilação e perfil volátil do óleo essencial de aroeira da praia (Schinus terebinthifolius) em Sergipe
}

OLIVEIRA, L.F.M. ${ }^{1}$; OLIVEIRA JR, L.F.G. ${ }^{2}$ SANTOS, M.C. ${ }^{3}$; NARAIN, N. ${ }^{4}$; LEITE NETA, M.T.S. ${ }^{4}$

${ }^{1}$ Bolsista CNPq, programa de Pós-Graduação em Agroecossistemas, Universidade Federal de Sergipe, 49.100000, São Cristovão - SE, Brasil. Autor para correspondência: lucasfmoliveira@gmail.com; ${ }^{2}$ Departamento de Engenharia Agronômica, UFS, Av. Marechal Rondon, Campus Universitário, 49100-000, São Cristóvão-SE, Brasil.; ${ }^{3}$ Bolsista CAPES, programa de Pós-Graduação em Agroecossistemas, Universidade Federal de Sergipe, 49.100-000, São Cristovão - SE, Brasil. ${ }^{4}$ Departamento de Tecnologia de Alimentos, UFS, Av. Marechal Rondon, Campus Universitário, 49100-000, São Cristóvão-SE, Brasil.

RESUMO: Aos frutos e óleos essenciais da aroeira da praia (Schinus terebinthifolius) atribui-se atividade antimicrobiana sobre bactérias gram positivas além de ação anti-inflamatória. O óleo essencial da aroeira é utilizado no tratamento de micoses, sendo a sua atividade antifúngica atribuída à alta concentração de monoterpenos. Este estudo teve como objetivo determinar o melhor rendimento de destilação de óleo essencial de sementes e folhas da aroeira e os componentes químicos do óleo essencial nos diversos períodos de destilação. Cem gramas de cada material foram destilados em aparato de Clevenger durante 2,5h, 4,0h, 5,5h e 7,0h. O material destilado foi analisado por cromatografia a gás acoplada a espectrofotômetro de massas, onde foi obtido o perfil cromatográfico do material. As sementes de aroeira apresentaram maiores quantidades de óleo essencial, quando comparadas com as folhas em todos os períodos de destilação. O óleo essencial de aroeira mostrou perfil volátil formado principalmente por mono e sesquiterpenos.

Palavras-chave: Aroeira, Sementes, CG/EM, Óleo essencial.

ABSTRACT: Distillation time and volatile profile of the essential oil of Brazilian pepper (Schinus terebinthifolius) in Sergipe, Brazil. The fruits and essential oils of Brazilian pepper (Schinus terebinthifolius) have antimicrobial activity against gram-positive bacteria, as well as anti-inflammatory action. The essential oil of Brazilian pepper is used to treat fungal infections, and its antifungal activity is attributed to the high concentration of monoterpenes. This study aimed to determine the best yield of distillation of the essential oil of seeds and leaves of Brazilian pepper and the chemical components of the essential oil in different periods of distillation. One hundred grams of each material were distilled in Clevenger apparatus for $2.5 \mathrm{~h}, 4.0 \mathrm{~h}, 5.5 \mathrm{~h}$ and $7.0 \mathrm{~h}$. The distilled material was analyzed by gas chromatography coupled to mass spectrometer, where the chromatographic profile of the material was obtained. Seeds of Brazilian pepper showed higher amounts of essential oils when compared with the leaves in all the periods of distillation. The essential oil of Brazilian pepper showed a profile consisting mainly of volatile mono- and sesquiterpenes.

Keywords: Brazilian pepper, Seeds, GC/MS, Essential oil.

\section{INTRODUÇÃO}

Nos últimos anos, vem ocorrendo no Brasil aumento acentuado no uso de plantas medicinais. A partir dessas plantas, princípios ativos são extraídos para a fabricação de medicamentos utilizados para o tratamento e cura de doenças (fitoterapia). Movimentando bilhões de dólares por ano, empresas farmacêuticas têm buscado no Brasil, ou em países com capacidade produtiva semelhante, princípios, essências e formulações para a obtenção de medicamentos e vacinas (Agrianual, 2002). Mesmo contando com mercado consumidor crescente, a produção de plantas medicinais e de seus produtos apresenta grandes falhas, demandando pesquisas para potencializar a produção e, consequentemente, o rendimento dos produtores.

Schinus terebinthifolius Raddi é conhecida 
como aroeira da praia e pertence à família Anacardiaceae, sendo uma espécie de origem no continente Sul americano. Pode ser encontrada desde o Estado do Ceará até o Rio Grande do Sul. É uma planta típica da caatinga brasileira, indicada para a recuperação de áreas degradadas e arborização. No Estado de Sergipe a aroeira vem sendo utilizada na ornamentação de praças e avenidas (Santos et al., 2009; Lorenzi \& Matos, 2008; Lenzi \& Orth, 2004).

A aroeira da praia apresenta propriedades adstringentes, antidiarreicas, depurativas, diuréticas e febrífugas. Aos seus frutos e óleos essenciais atribui-se atividade antimicrobiana sobre bactérias gram positivas além de ação anti-inflamatória. 0 óleo essencial dessa planta é utilizado através de aplicações tópicas no tratamento de micoses e candidíases, sendo a atividade antifúngica atribuída à alta concentração de monoterpenos (Costa et al., 2010; Lima et al., 2006; Pires et al., 2004).

Estudos fitoquímicos revelaram a presença de diversos compostos químicos, incluindo alcoóis, cetonas, ácidos, monoterpenos, sesquiterpenos e triterpenos no caule, folhas e frutos da aroeira da praia (Carvalho et al., 2003; Santos et al., 2006).

Analisando a composição química do óleo essencial de frutos de aroeira da praia, Ibrahim et al. (2010) observaram a predominância de monoterpenos, principalmente os terpenos: $\alpha$-pineno, germacrenoD, canfeno, $\beta$-felandreno, $\gamma$-terpineno, $\alpha$-felandreno e $\delta$-3-careno. $O$ teor desses monoterpenos chegou a $40 \%$ da composição química das amostras de óleo essencial verificado por daqueles autores.

Segundo Ranasinghe et al. (2002), os óleos essenciais são produzidos em diferentes partes da planta e apresentam várias funções na mesma, incluindo resistência a pragas e doenças.

O tempo de destilação é um fator preponderante na composição química dos óleos essenciais, sendo esta influenciada diretamente pelo tempo de exposição do material vegetal as temperaturas da destilação. Simões \& Spitzer (2003), sugerem que o calor e a pressão usados no ato da extração podem, por exemplo, interferir na qualidade final do óleo essencial, pois no momento da extração as sensíveis moléculas dos princípios ativos podem ser degradadas em produtos com menor eficácia ou até tóxicos.

Desta forma, o presente trabalho teve como objetivo determinar o tempo de destilação que proporcione o melhor rendimento do óleo essencial de sementes e folhas de aroeira da praia (Schinus terebinthifolius Raddi), além de determinar os principais constituintes químicos deste óleo essencial.

\section{MATERIAL E MÉTODOS}

Os trabalhos foram realizados no Laboratório de Ecofisiologia e Pós-Colheita (ECOPOC) do Departamento de Engenharia Agronômica e no Laboratório de Flavour e Análises Cromatográficas (LAF) do Programa de Pós-Graduação em Ciências e Tecnologia de Alimentos, ambos da Universidade Federal de Sergipe, São Cristovão - SE.

Sementes de aroeira da praia (Schinus terebinthifolius Raddi) foram colhidas no Campus da Universidade Federal de Sergipe quando apresentavam coloração vermelho intenso, indicando a maturação das mesmas. Após o desgalhamento, estas foram secas em temperatura ambiente durante 48h para a estabilização da sua massa.

Folhas de aroeira da praia foram colhidas quando estavam totalmente expandidas e fotossinteticamente ativas e secas em estufa de circulação forçada de ar durante quatro dias a temperatura constante de $40^{\circ} \mathrm{C}$. Amostras botânicas do material estão guardadas no Herbário da Universidade Federal de Sergipe sob exsicata $n^{\circ}$ 23108.

Passado o período de secagem, amostras de $100 \mathrm{~g}$ foram pesadas e trituradas em liquidificador semi-industrial (400W) até atingirem granulometria uniforme. O material foi colocado em balão de fundo redondo com capacidade para $2 \mathrm{~L}$, onde foi acrescentado $1 \mathrm{~L}$ de água destilada. $\mathrm{O}$ balão foi acoplado ao aparato de destilação do tipo Clevenger e o sistema foi isolado da luz e ligado em potência máxima até o inicio da destilação. A partir do inicio da destilação, a temperatura do sistema foi ajustado até o ponto de ebulição do líquido (aproximadamente $95^{\circ} \mathrm{C}$ ) e teve início a contagem de tempo da mesma (2,5h; 4,0h; 5,5h; 7,0h).

Ao término de cada tempo de destilação o aquecimento foi desligado e foi feita a separação do material aquoso do óleo essencial. Cada material colhido foi quantificado e acondicionado em frasco âmbar à baixa temperatura $\left(-18^{\circ} \mathrm{C}\right)$ para evitar degradação de seus constituintes.

O rendimento do óleo de semente e de folhas de aroeira foi calculado através da relação volume/massa: Volume de óleo obtido $(\mathrm{mL}) /$ Peso de material vegetal destilado (g)x 100 .

A determinação da composição química dos óleos de sementes e de folhas de aroeira da praia foi realizada utilizando-se um Cromatógrafo a Gás da marca Varian, modelo 4000, acoplado a um Espectrofotômetro de Massas (EM) e equipado com uma coluna capilar CP-WAX52CB, (30 m x 0,25 $\mathrm{mm} \times 0,25 \mu \mathrm{m}$ ), sendo o hélio 5.0 o gás carreador. As condições de operação do cromatógrafo a gás foram: pressão interna da coluna de 21,3 psi; razão de split de 1:50; fluxo de gás na coluna de $1 \mathrm{~mL} / \mathrm{min}$.; temperatura do injetor de $220^{\circ} \mathrm{C}$; temperatura do

Rev. Bras. PI. Med., Campinas, v.16, n.2, p.243-249, 2014. 
detector de $260^{\circ} \mathrm{C}$; Programação da temperatura da coluna: Inicio a $60^{\circ} \mathrm{C}$ aquecendo até $240^{\circ} \mathrm{C}$ numa taxa de aquecimento de $3^{\circ} \mathrm{C} / \mathrm{min}$., permanecendo nessa temperatura durante $10 \mathrm{~min}$, totalizando 70 min de análise.

Uma pequena alíquota do óleo essencial $(50 \mu \mathrm{L})$ foi transferida com o auxílio de micropipeta para um recipiente limpo e seco onde foi diluída com $250 \mu \mathrm{L}$ de hexano na razão de 1:6. Para a completa retirada de água da amostra foi adicionada uma pequena quantidade de sulfato de sódio anidro $\left(\mathrm{Na}_{2} \mathrm{SO}_{4}\right)$. Com o auxílio de uma microseringa coletou-se $0,5 \mu \mathrm{L}$ desta solução e a amostra foi injetada no aparelho.

A identificação das substâncias foi efetuada através da comparação dos índices de retenção de Kovàts obtidos experimentalmente com os valores tabelados (Adams, 2001). Também foi utilizada a biblioteca do equipamento (NIST - Natural Institute of Standards \& Tecnology, USA) que permite a comparação dos espectros obtidos das amostras com aqueles constantes da biblioteca.

O delineamento experimental foi inteiramente casualizado em esquema fatorial 2x4 (Material vegetal $X$ Tempo de destilação), com 3 repetições. Totalizando 8 tratamentos $\left(T_{1}=\right.$ Sementes destiladas durante $2,5 \mathrm{~h} ; \mathrm{T}_{2}=$ Sementes destiladas durante $4,0 \mathrm{~h} ; \mathrm{T}_{3}=$ Sementes destiladas durante $5,5 \mathrm{~h} ; \mathrm{T}_{4}=$ Sementes destiladas durante $7,0 \mathrm{~h}$; $\mathrm{T}_{5}=$ Folhas destiladas durante $2,5 \mathrm{~h} ; \mathrm{T}_{6}=$ Folhas destiladas durante $4,0 \mathrm{~h} ; \mathrm{T}_{7}=$ Folhas destiladas durante $5,5 \mathrm{~h} ; \mathrm{T}_{8}=$ Folhas destiladas durante $7,0 \mathrm{~h}$ ) e 24 parcelas experimentais. Os resultados foram analisados a $5 \%$ de probabilidade pelo teste de Skott-Knott.

\section{RESULTADOS E DISCUSSÃO}

\section{Obtenção de óleo essencial de sementes e folhas de aroeira da praia}

Analisando-se os rendimentos obtidos durante a extração dos óleos essenciais de aroeira da praia (Tabela1), observou-se que as sementes de aroeira continham quantidades significativamente maiores de óleo essencial do que as folhas dessa planta.

Os valores superiores de óleo essencial nas sementes de aroeira era esperado em função destas serem órgãos de reserva da planta e por apresentarem estrutura celular adaptada para o acúmulo de nutrientes e solutos que são utilizados no desenvolvimento do embrião quando este inicia o processo de germinação. Além disso, o acúmulo de substâncias odoríferas nas sementes pode ser de grande importância como estratégia evolutiva para atrair animais que possam vir a se alimentar das mesmas dispersando-as e possibilitando o crescimento de novos indivíduos em outras regiões. Fato também relatado por Simões \& Spitzer, (2003), onde afirmam que os óleos essenciais podem ser produzidos por diversas estruturas existentes nos diversos órgãos da planta apresentando rendimento, composição química e características físicas e químicas distintas.

Os diversos tempos de destilação não resultaram em diferenças significativas nos teores de óleo essencial tanto em folhas quanto em sementes de aroeira, apresentando $0,1 \%$ e $2,86 \%$ como maiores rendimentos de óleo em folhas e sementes, respectivamente. O baixo rendimento de óleo essencial obtido das folhas de aroeira inviabiliza a sua utilização quando comparado à quantidade de óleo obtida pela destilação das sementes desta planta. Diferença também observada por Barboza et al., (2007), quando extraíram óleo de folhas e sementes de aroeira da praia, reportando valores de $0,44 \%$ e $4,65 \%$, respectivamente.

A pequena variação nos teores de óleo essencial de semente observada nos diferentes períodos de destilação não foi significativa. Desta forma a utilização de $2,5 \mathrm{~h}$ de destilação tornouse mais adequada por expor o material vegetal a altas temperaturas por um menor período de tempo diminuindo assim a degradação de alguns componentes químicos do óleo que apresentam maior sensibilidade ao calor. Como indicado por Simões \& Spitzer, (2003), onde o calor e a pressão usados no ato da extração podem, por exemplo, interferir na qualidade final do óleo essencial, pois

TABELA 1. Rendimento do óleo essencial de aroeira da praia obtido de folhas e sementes em diferentes tempos de destilação.

\begin{tabular}{lllll}
\hline \multirow{2}{*}{ Parte vegetal } & \multicolumn{4}{l}{ Tempo de Destilação } \\
\cline { 2 - 5 } & $2,5 \mathrm{~h}$ & $4,0 \mathrm{~h}$ & $5,5 \mathrm{~h}$ & $7,0 \mathrm{~h}$ \\
\hline Folha & $0,10 \% \mathrm{Aa}$ & $0,06 \% \mathrm{Aa}$ & $0,10 \% \mathrm{Aa}$ & $0,10 \% \mathrm{Aa}$ \\
Semente & $2,76 \% \mathrm{Ab}$ & $2,66 \% \mathrm{Ab}$ & $2,36 \% \mathrm{Ab}$ & $2,86 \% \mathrm{Ab}$ \\
\hline CV: & $15,94 \%$ & & & \\
\hline
\end{tabular}

Valores seguidos da mesma letra maiúscula na linha não diferem entre si pelo teste de Skott-Knott a 5\% de probabilidade; Valores seguidos da mesma letra minúscula na coluna não diferem entre si pelo teste de Skott-Knott a $5 \%$ de probabilidade. 
no momento da extração as sensíveis moléculas de um princípio ativo, em sua maioria terpenos, podem ser quebradas e oxidadas em produtos de menor eficácia, ou às vezes até tóxico.

Os teores constantes de óleo essencial nas sementes e folhas de aroeira da praia obtidos após poucas horas de destilação indicam que os compostos existentes nessa planta são de fácil volatilização, possivelmente por apresentarem baixo peso molecular e consequente baixa temperatura de ebulição. Como observado por Cole, (2008), Santos et al., (2009) e Santos et al., (2007), o óleo essencial da aroeira tem como componentes majoritários vários monoterpenos, hidrocarbonetos com cadeia formada por 10 carbonos, que conferem ao óleo densidade e peso molecular menores aos encontrados no óleo essencial de outras plantas.

\section{Determinação da composição química do óleo essencial de sementes de aroeira da praia.}

A quantidade extremamente pequena de óleo essencial obtida a partir das folhas de aroeira da praia impossibilitou a determinação de compostos voláteis presentes no mesmo demonstrando a inviabilidade do processo da comercialização do mesmo. A partir das informações contidas na Tabela 2, observa-se que foram identificados 16 compostos majoritários, totalizando mais de $91 \%$ da composição química do óleo essencial de aroeira após os diversos períodos de destilação, exceto para o tempo de $2,5 \mathrm{~h}$. O óleo essencial apresentou composição bastante uniforme em todos os períodos de destilação variando na quantidade de cada componente após determinado tempo de destilação. Após 2,5h de destilação o óleo apresentou o composto $\rho$-menth-1-en-9-ol como majoritário, enquanto que os demais óleos essenciais continham o p-menth-1-en-9-ol, o canfeno, o germacreno-D, o hedicariol, o $\alpha$-gurjuneno, o $\alpha$-eudesmol e o $\beta$-eudesmol como compostos majoritários.

Observa-se na Figura 1, que ao longo da destilação houve um decréscimo na quantidade de monoterpenos encontrados no óleo essencial; em contrapartida, houve aumento na quantidade de sesquiterpenos com o aumento do tempo de destilação do mesmo. A alteração na composição pode ser em decorrência também da perda dos compostos mais voláteis (monoterpenos) por volatilização, devido ao maior tempo de extração.

Os diversos períodos de destilação alteraram as concentrações de determinados compostos no óleo essencial de aroeira aumentando significativamente a concentração de compostos menos voláteis como, por exemplo, canfeno, $\alpha$-fencheno, germacreno- $D, \delta$-cadineno, hedicariol, $\alpha$-gurjuneno, $\alpha$-eudesmol e $\beta$-eudesmol, nos

TABELA 2. Compostos voláteis identificados no óleo essencial extraído de sementes de aroeira da praia destilado por diferentes períodos.

\begin{tabular}{|c|c|c|c|c|c|c|c|}
\hline \multirow{2}{*}{ Composto } & \multirow{2}{*}{ T. R. } & \multirow{2}{*}{$\begin{array}{l}\text { IR } \\
\text { Calculado }\end{array}$} & \multirow{2}{*}{$\begin{array}{l}\text { IR } \\
\text { Tabelado }\end{array}$} & \multicolumn{2}{|c|}{ Tempo de Destilação } & \multirow[b]{2}{*}{$\% 5,5 h$} & \multirow[b]{2}{*}{$\% 7,0 h$} \\
\hline & & & & $\% 2,5 h$ & $\% 4,0 h$ & & \\
\hline p-Mmenth-1-en-9-ol & 4,393 & 1154,49 & 1154 & 35,340 & 29,128 & 8,277 & 9,381 \\
\hline$\beta$-pineno & 4,527 & 1162,27 & 1162 & 2,559 & 2,712 & 1,289 & 1,372 \\
\hline a-tujeno & 4,586 & 1165,86 & 1165 & 1,993 & 1,893 & 1,262 & 1,443 \\
\hline Canfeno & 5,210 & 1198,80 & 1199 & 2,131 & 5,110 & 4,785 & 5,268 \\
\hline$\alpha-$ fencheno & 5,401 & 1208,75 & 1208 & 2,438 & 8,201 & 8,463 & 9,467 \\
\hline acetato de terpinen-4-ol & 7,131 & 1283,75 & 1283 & 1,289 & 1,014 & 0,619 & 0,619 \\
\hline acetato de bornila & 16,646 & 1564,28 & 1564 & 0,328 & 1,533 & 1,697 & 1,820 \\
\hline Cariofileno & 17,218 & 1578,57 & 1578 & 0,571 & 1,851 & 2,091 & 1,965 \\
\hline terpinen-4-ol & 17,540 & 1586,73 & 1586 & 0,204 & 0,880 & 1,387 & 1,339 \\
\hline a-terpineol & 20,970 & 1680,00 & 1680 & 0,179 & 1,073 & 1,410 & 1,352 \\
\hline germacreno - D & 21,193 & 1686,25 & 1685 & 2,055 & 6,943 & 7,922 & 7,917 \\
\hline ס-cadineno & 23,028 & 1729,32 & 1729 & 1,005 & 1,005 & 1,094 & 1,010 \\
\hline Hedicariol & 33,754 & 2050,44 & 2050 & 3,175 & 11,626 & 18,634 & 18,837 \\
\hline a-gurjuneno & 36,320 & 2109,14 & 2109 & 2,326 & 8,343 & 12,133 & 11,747 \\
\hline a-eudesmol & 37,825 & 2237,76 & 2237 & 1,936 & 6,757 & 9,177 & 8,310 \\
\hline$\beta$-eudesmol & 38,018 & 2284,45 & 2284 & 2,417 & 7,987 & 11,151 & 9,946 \\
\hline Outros & & & & 40,054 & 3,944 & 8,609 & 8,207 \\
\hline
\end{tabular}

T.R.: Tempo de Retenção em minutos. IR:índice de retenção 


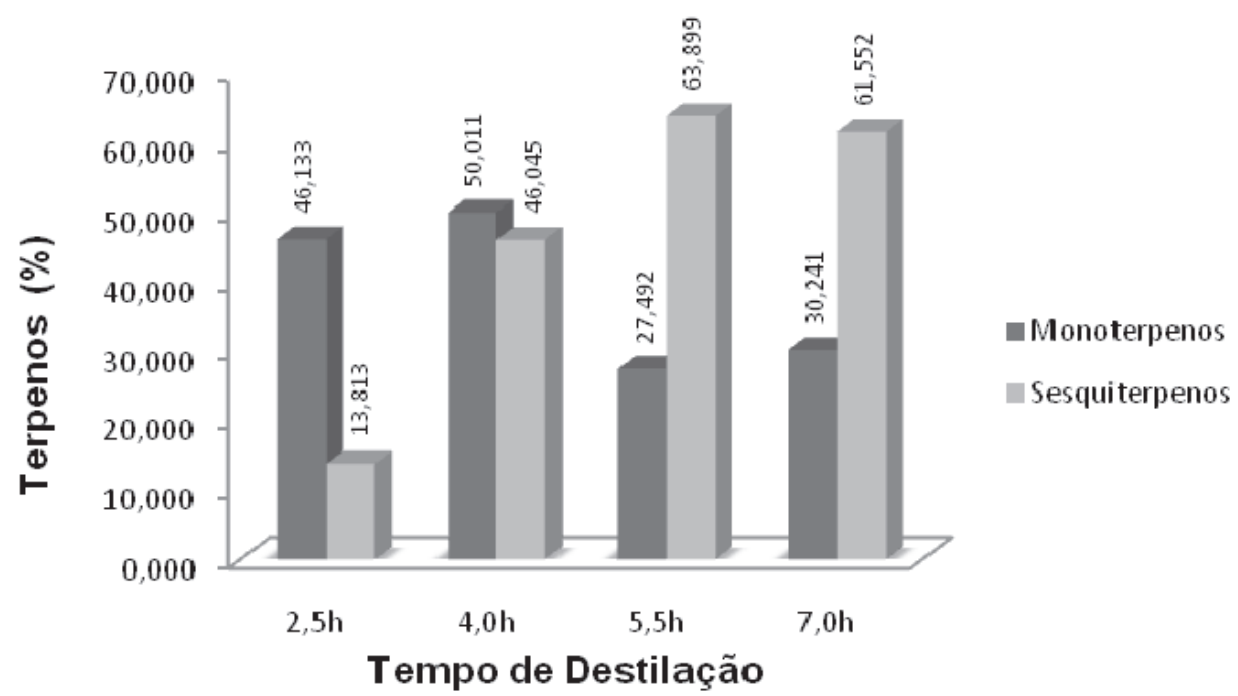

FIGURA 1.Percentagem de mono e sesquiterpenos no óleo essencial extraído de sementes de aroeira destiladas por 2,5h, 4,0h, 5,5h e 7,0h.

óleos destilados durante 4,0h, 5,5h e 7,0h quando comparados ao óleo destilado durante $2,5 \mathrm{~h}$. Observou-se também que houve uma redução significativa nas concentrações de $\rho$-menth-1-en9-ol, quando foram comparados os óleos obtidos com 2,5h,4,0h, 5,5h e 7,0h de destilação (Figura 2).

Este fato também foi observado por Barboza et al., (2007), quando extraíram óleo essencial de sementes e folhas de aroeira da praia e notaram elevação na concentração de compostos menos voláteis (sesquiterpenos) e redução na concentração de compostos mais voláteis (monoterpenos) ao longo do aumento do período de destilação.

O perfil fitoquímico do óleo essencial obtido neste trabalho é diferente do apresentado por outros autores, Cole, (2008), Barboza et al., (2007), Santos et al., (2007) e Keweka et al., (2011), onde se verificou, por exemplo, a presença de $\alpha$-felandreno, $\beta$-felandreno, elemol, $\alpha$-cadiol, sabineno, $\delta$-3-careno e silvestreno, enquanto que neste trabalho não

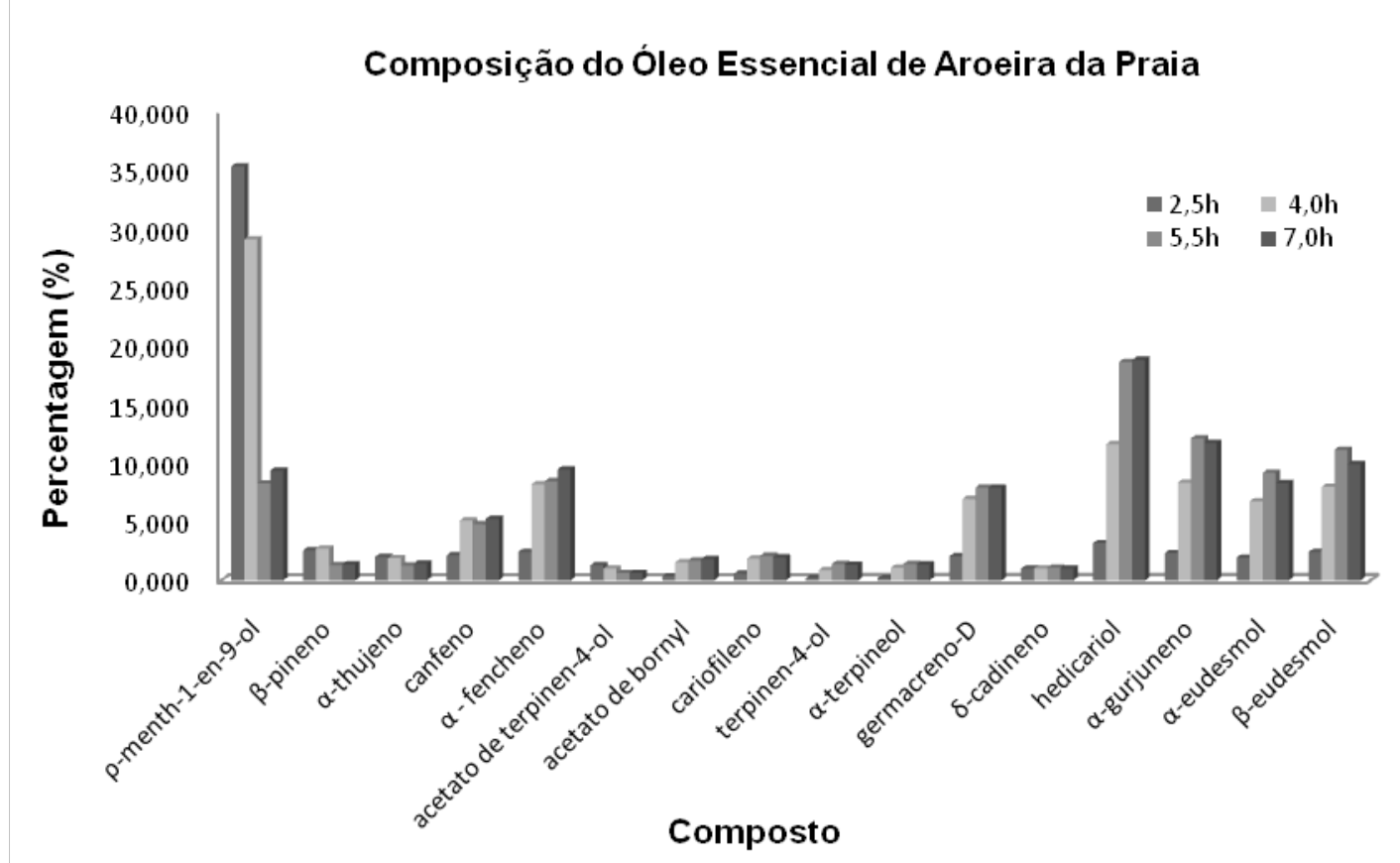

FIGURA 2. Teor de compostos voláteis do óleo essencial de sementes de aroeira da praia destiladas por diferentes períodos. 
foram observados esses compostos, evidenciando que as características genéticas da planta e os fatores abióticos interferem significativamente na composição química do óleo essencial de aroeira. Este fato também foi observado por Ibrahim et al., (2010), que relataram a grande variação da composição química dos óleos essenciais de plantas ligadas diretamente a fatores genéticos e ambientais e por Martins et al., (2006), que também constataram variação na composição química do óleo essencial de Hyptis suavenoles em diferentes condições de cultivo.

Assim, a exposição por longo período de destilação para a obtenção do óleo essencial a temperaturas elevadas pode modificar as concentrações de seus compostos majoritários, da mesma forma que a genética e o fator ambiente podem alterar a concentração e a composição dos óleos essenciais de aroeira da praia.

\section{CONCLUSÕES}

As sementes de aroeira da praia apresentam quantidades superiores de óleo essencial quando comparadas com as folhas;

A destilação com duração de 2,5 h é o período ótimo para a obtenção do óleo essencial de Schinus terebinthifolius;

O óleo essencial de aroeira da praia apresenta um perfil volátil composto em sua maioria por $\rho$-menth-1-en-9-ol, $\alpha$-tujeno, $\beta$-pineno, canfeno, $\alpha-f e n c h e n o$, acetato de terpinen-4-ol, acetato de bornila, cariofileno, terpinen-4-ol, a-terpineol, germacreno-D, $\delta$-cadineno, hedicariol, $\alpha$-gurjuneno, $\alpha$-eudesmol, $\beta$-eudesmol.

O aumento no tempo de destilação altera os teores dos compostos do óleo essencial.

\section{AGRADECIMENTOS}

Agradecemos ao Conselho Nacional de Desenvolvimento Cientifico e Tecnológico (CNPq) e a Universidade Federal de Sergipe pelo apoio estrutural e financeiro para a realização deste trabalho.

\section{REFERÊNCIA}

ADAMS, R.P. Identification of Essential Oil Components by Gas Chromatography/Mass Spectroscopy. Carol Stream: Allured Publishing Corporation. 2001. 804p.

AGRIANUAL. Pelo aproveitamento racional das plantas medicinais da Amazônia. FNPConsultoria e Comércio, p. 28-29, 2002.

BARBOSA, L.C.A.; DEMUNER, A.J.; CLEMENTE, A.D. Seasonal Variation in the Composition of Volatile Oils from Schinus terebinthifolius RADDI. Química Nova, v. 30, n.8, p. 1959-1965, 2007.
CARVALHO, M.C.; BARCA, F.N.; AGNEZ-LIMA, F.L.; de MEDEIROS, S.R. Evaluation of mutagenic activity in an extract of pepper tree stem bark (Schinus terebinthifolius Raddi). Environmental and Molecular Mutagenesis, v. 42, n. 3, p. 185-191, 2003.

COLE, E.R. Estudo Fitoquímico do Óleo Essencial dos Frutos da Aroeira (Schinus terebinthifolius Raddi) e sua Eficiência no Combate ao Dengue. 2008. 82p. Dissertação (Mestrado), Universidade Federal do Espírito Santo. Vitória.

COSTA, E.M.M.B.; BARBOSA, A.S.; ARRUDA, T.A.; OLIVEIRA, P.T.; DAMETTO, F.R.; CARVALHO, R.A.; MELO, M.D. Estudo in vitro da Ação Antimicrobiana de Extrato de Plantas contra Enterococcus faecalis. Jornal Brasileiro de Patologia Medica e Laboratorial, v. 46, n. 3, p. 175-180, 2010.

IBRAHIM, M.A.; MÄENPÄÄ, M.; HASSINEN, V.; KONTUNEN-SOPPELA, S.; MALEC, L.; ROUSI, M.; PIETIKÄINEN, L.; TERVAHAUTA, A.; KÄRENLAMPI, S.; HOLOPAINEN, J.K.; OKSANEN, E.J. Elevation of night-time temperature increases terpenoid emissions from Betula pendula and Populus tremula. Journal of Experimental Botany, v. 61, n. 6, p. 1583-1595, 2010.

KWEKA, E.J.; NYINDO, M.; MOSHA, F. SILVA, A.G. Insecticidal Activity of the Essential Oil from Fruits and Seeds of Schinus terebinthifolia Raddi Against African Malaria Vectors. Parasites \& Vectors, v. 4, n.129 10p. 2011.

LENZI, M.; ORTH, A.I. Caracterização Funcional do Sistema Reprodutivo da Aroeira Vermelha (Schinus terebinthifolius Raddi), em Florianópolis - SC, Brasil. Revista Brasileira de Fruticultura, Jaboticabal - SP, v. 26, n. 2, p. 198-201, 2004.

LIMA, M.R.F.; LUNA, J.S.; SANTOS, A. F.;ANDRADE, M.C.C.; SANT'ANA, A.E.G.; GENET, J-P.; MARQUEZ, B.; NEIVILLE, L.; MOREAU, N. Anti-bacterial Activity of some Brazilian Medicinal Plants. Journal of Ethnopharmacology, v. 105, p. 137-147, 2006.

LORENZI, H.; MATOS, F.J.A. Plantas Medicinais do Brasil - Nativas e Exóticas. Ed. Plantarum: Nova Odessa - SP; $2^{\mathrm{a}}$ ed., p. 63-64, 2008.

MARTINS, F.T.; SANTOS, M.H.; POLO, M. Variação Química do Óleo Essencial de Hyptis suaveolens (L.) POIT., sob Condições de Cultivo. Química Nova, v. 29, n. 6, p. 1203-1209, 2006.

PIRES, O.C.; TAQUEMASA, A.V.C.; AKISUE, G.; OLIVEIRA, F.; ARAÚJO, C.E.P. Análise preliminar da toxidade aguada e dose letal mediana $\left(\mathrm{DL}_{50}\right)$ comparativa entre os frutos de Pimenta do Reino do Brasil (Schinus terebinthifolius Raddi) e Pimenta do Reino (Piper nigrum L). Acta Farmacéutica Bonarense, v. 23, n. 02, p. 176-182, 2004.

RANASINGHE, L.; JAYAWARDENA, B. e ABEYWICKRAMA, K. Fungicidal activity of essential oils of Cinnamomum zeylanicum (L.) and Syzygium aromaticum (L.) Merr et L.M.Perry against crown rot and anthracnose pathogens isolated from banana. Letters in Applied Microbiology. v. 35, p.208-211. 2002.

SANTOS, A.C.A. dos; ROSSATO, M.; AGOSTINI, F.; SERAFINI, L.A.; SANTOS, P.L. dos; MORLON, R.; DELLACASSA, E.; MOYNA, P. Chemical composition of the essential oils from leaves and fruits of Schinus molle L. and Schinus terebinthifoliusRaddi from southern

Rev. Bras. PI. Med., Campinas, v.16, n.2, p.243-249, 2014. 
Brazil. Journal of Essential Oil-Bearing Plants, v. 12, n. 1, p. 16-25, 2009.

SANTOS, M.R.A.; LIMA, R.A.; FERNANDES, C.F.; SILVA, A.G.; LIMA, D.K.S.; TEIXEIRA, C.A.D.; FACUNDO, V.A. Atividade inseticida do óleo essencial de Schinus terebinthifolius Raddi sobre Acanthoscelides obtectus Say e Zabrotes subfasciatus Boheman. Revista Fitos, v. 3,n. 1, p. 77-84, 2007.

SANTOS, O.J.; RIBAS FILHO, J.M.; CZECZKO, N.G.; NETO, M.L.C.B.; NAUFEL JR., C.; FERREIRA,
L.M.; CAMPOS, R.P.; MOREIRA, H.; PORCIDES, R.D.; DOBROWOLSKI, S. Avaliação do Extrato de Aroeira (Schinus terebinthifolius RADDI) no Processo de Cicatrização de Gastrorrafias em Ratos. Acta Cirúrgica Brasileira, v. 21, n. 2, p. 39-45, 2006.

SIMÕES, C.M.O. \& SPITZER, V. Óleos voláteis. In: Farmacognosia: da planta ao

medicamento. $5^{\circ}$ ed. Porto Alegre/Florianópolis: Editora da UFRGS/ Editora da UFSC, p. 467-496. 2003. 